\title{
GACOCA Formulation of East African Wild Mushrooms Show Promise in Combating Kaposi's Sarcoma and HIV/ AIDS
}

\author{
Julius David Sumba \\ Mushroom Practitioner Box 698 Ifakara, Tanzania, Tel. 255748 399981, email: \\ juliussumba@hotmail.com
}

Preliminary studies involving the use of a formulation comprising a mixture of powdered fruit bodies of several wild medicinal East African mushrooms in the treatment of patients with Kaposi's sarcoma (an opportunistic skin cancer affecting patients afflicted with HIV/AIDS) show promising therapeutic results. The same product has also benefited patients with HIV/AIDS.

The product, GACOCA, has been used in Tanzania since 2001. Initially it was used to treat patients with HIV/AIDS in Ifakara Morogoro in central Tanzania under the supervision of Dr. Henry Moshi of St. Francis Hospital, who found that patients achieved noticeable improvement in health. Later, trials in Dare s-Salaam on patients with Kaposi's sarcoma revealed encouraging responses with complete resolution of the condition in a fraction of these patients. GACOCA has also demonstrated promising effectiveness in other conditions including diabetes, high blood pressure, libido problems, and bedwetting. These encouraging medicinal values of the GACOCA mushroom warrant further evaluation in properly designed clinical trials.

GACOCA contains several mushrooms of established medicinal value, which are abundantly available in the East African woodlands. I list them below according to their botanical names.

- Ganoderma species include G. lucidum (W.Curt.: Fr.) Lloyd, G. applanatum (Pers.:Wallr.) Pat., and G. pfeifferi Bres. Ganoderma species have been extensively researched. Their antitumor, antiviral, cholestrol reducing, and anti-fatigue effects have been demonstrated. Many of the vast numbers of its polysaccharides and triterpernoids studied so far show immunomodulatory properties. Triterpernoids inhibit cholesterol synthesis, allergenic responses, and histamines. In addition, anti-inflammatory, antibiotic, antifungal, antiaging, and stamina-enhancing effects have been mentioned. Extracts of this mushroom prevented the death of lymphocytes infected with HIV and inhibited the replication of the virus within the mother and daughter cells.

- Trametes versicolor (L.:Fr.) Lloyd (=Coriolus versicolor) (Turkey tail) has immune enhancement, antitumor, antiviral, antibacterial, and antioxidant properties. PSK, a derivative of this mushroom, is an approved anticancer drug in Asia. The drug is popularly used in the treatment of stomach cancer, among others. Another form of extract, PSP, is an antiviral agent inhibiting HIV replication based on in vitro studies. This is probably the most well-documented medicinal mushroom according to authorities in medicinal mushrooms.

- Cantharellus species include C. cibarius Fr.:Fr., $C$. cornucopioides (L.) Fr., and C. isabellinus Heinem. These mushrooms are abundantly available in Tanzania and contain essential amino acids as 
well as vitamin A. Consumption of these mushrooms is beneficial in preventing night blindness, inflammation of the eyes, and dry skin, according to traditional Chinese medicine. It also helps to tonify the mucus membranes and may increase resistance against certain infectious diseases of the respiratory tract. Studies in mice show that ethanol extract of $C$. cibarius sporophore can inhibit growth of sarcoma 180 (a type of experimental animal cancer).

Some mushrooms such as Schizophyllum commune Fr.:Fr., Phellinus igniarus (L.) Quel., and Fomes fomentarius (L.) J.J. Kickx are mixed in GACOCA. These species of the woody mushroom are common in East Africa. Traditional healers in the regions use the mushroom as medication. It is claimed, that mixed in various proportions, they could be effective in treating epilepsy and general chest pain. The treatment is performed by having patient inhale smoke from a burning substance under a cloth hood, by inhaling vapor from boiling substances, and sometimes by taking the liquid in a cup of tea. These mixtures are also used locally for the treatment of mental disorders (claimed in the traditional medicine setting to remove demons).

The literature reports that these mushrooms can heal the inflammation of the brain (as in Alzheimer's disease) at early stages. Phellinus linteus (Berk. et M.A. Curt.) Teng is a more familiar product in the medical literature. It has antitumor and immunomodulating properties, especially in the enhancement of activity of B lymphocytes. Studies reported in 2000 found that this mushroom had the highest rate of inhibition against implanted sarcoma cancer 180 in mice, resulting in $96.7 \%$ inhibition. A report in 2001 explored the antimutagenic properties of this mushroom, showing activity in limiting or preventing tumor development. Research in Korea led to the establishment of $\mathrm{Ph}$. linteus as a standard treatment for cancer.

The mushroom species described above have been identified in large quantities in Tanzania and East Africa, and we are working with hospital clinicians, natural therapists, and traditional healers to study their medicinal value in our settings. It is my intention to make this information available so that the GACOCA mushroom will interest scientists, medical professionals, environmentalists, the business community, educators, and any other stakeholders in the region and the world. I believe there is big potential here, especially now when pollution is already a concern elsewhere in the world.

I was introduced to this mushroom back in 1967. At that time I was staying in Sigulu Island on lake Victoria, Uganda, with my grandmother Veronica Ajiambo, who adopted me after the death of my father in 1963 at Jipe, Mwanga in Kilimanjaro, Tanzania. She taught me the art of identifying and picking mushrooms.

In 1980 I learned about mushroom cultivation. In 1993 I started collecting mushroom literature from the best world authorities. I read all I could about mushrooms, cultivated them, collected them, identified them, and worked with local consultants to design clinical trials.

Today in Tanzania the GACOCA mushroom is being used as an immune booster by patients with $\mathrm{HIV}^{+}$, Kaposi's sarcoma, and arthritis, among other illnesses. Through HBCPs (home based care providers) the GACOCA mushroom is distributed to the community in the Kibaha coast region. I work with KIDEFO (Kibaha Development Foundation) to support the community healthwise. We intend to expand the service countrywide, and expect to make GACOCA extracts in early 2005. The center for production of this mushroom is in Kibaha Maili moja coast region in Tanzania. It is collected from different regions in the country and processed for community. Some is sold to pharmaceutical shops and supermarkets to sustain the GACOCA project.

\section{ACKNOWLEDGMENTS}

COSTECH (Tanzania Commission for Science and Technology), Dare s-Salaam. Prof. Dr. Jeff Luande, Ocean Road Cancer Research Institute, Dar es Salaam, Tanzania. Dr. Flora Fabian, Holistic Family Clinic, India and Morogoro Road Junction, Dar es Salaam, Tanzania. Dr. Henry Moshi, Watani Dispensary, Ifakara Morogoro, Tanzania. 